The University of Maine

DigitalCommons@UMaine

Publications

Senator George J. Mitchell Center for Sustainability

Solutions

$8-2015$

\title{
Australians' views on carbon pricing before and after the 2013 federal election
}

Stacia J. Dreyer

University of Maine

Iain Walker

Shannon K. McCoy

University of Maine

Mario F. Teisl

University of Maine, teisl@maine.edu

Follow this and additional works at: https://digitalcommons.library.umaine.edu/ mitchellcenter_pubs

\section{Repository Citation}

Dreyer, Stacia J.; Walker, Iain; McCoy, Shannon K.; and Teisl, Mario F., "Australians' views on carbon pricing before and after the 2013 federal election" (2015). Publications. 14.

https://digitalcommons.library.umaine.edu/mitchellcenter_pubs/14 


\section{Australians' views on carbon pricing before and after the 2013 federalelection}

Stacia J. Dreyer ${ }^{1,2 *}$, lain Walker ${ }^{3,4}$, Shannon K. McCoy ${ }^{2}$ and Mario F. Teisl ${ }^{1}$

1 School of Economics, University of Maine, Orono, Maine 04469, USA.

2 Department of Psychology, University of Maine, Orono, Maine 04469, USA.

3 Commonwealth Scientific and Industrial Research Organisation, Floreat, Western Australia 6913, Australia. 
4 School of Psychology, University of Western Australia, Crawley, Western Australia 6009, Australia.

*email: sdreyer@uw.edu

As climate policies change through the legislative process, public attitudes towards them may change as well. Therefore, it is important to assess how people accept and support controversial climate policies as the policies change over time. Policy acceptance is a positive evaluation of, or attitude towards, an existing policy ${ }^{1-3}$; policy support adds an active behavioural component ${ }^{1,3}$. Acceptance does not necessarily lead to support. We conducted a national survey of Australian residents to investigate acceptance of, and support for, the Australian carbon pricing policy before and after the 2013 federal election, and how perceptions of the policy, economic ideology, and voting behaviour affect acceptance and support. We found acceptance and support were stable across the election period, which was surprising given that climate policy was highly contentious during the election. Policy acceptance was higher than policy support at both times and acceptance was a necessary but insufficient condition of support. We conclude that acceptance is an important process through which perceptions of the policy and economicideology influence support. Therefore, future climate policy research needs to distinguish between acceptance and support to better understand this process, and to bettermeasure these concepts.

The acceptability of an environmental policy usually increases between planning and implementation $^{4-6}$. This pattern is also evident in controversial health policies such as smoking restrictions ${ }^{7}$, but is not well established in the climate policy literature, where researchers have measured acceptability, acceptance, and/or support for climate policies only at single time points ${ }^{1,8}$. Increased acceptance and support may be due to increased familiarity ${ }^{9,10}$ with the policy or the realization that prior anxieties regarding perceived negative outcomes of the policy were unfulfilled ${ }^{4}$.

The role elections play in changing policy support and acceptance is poorly understood. We 
examined changes in support for, and acceptance of, Australia's carbon pricing policy using data collected a fortnight before and a fortnight after the 2013 federal election. The policy was a heated topic of debate during the election campaign. Regardless of familiarity processes, changes in carbon policy support and acceptance may reflect or drive changes in the government, but the literature does not lend itself to any firm hypothesis. If the newly elected government had sought to overturn an existing policy as part of its election platform, we may expect support and acceptance to diminish. If the incumbent government, which had introduced the policy, were re-elected, we may expect support and acceptance to increase. Many processes may account for such changes. People may alter their views to align with newly discovered population norms ${ }^{11}$, they may seek to resolve cognitive dissonance arising from differences between their views and the new status quo ${ }^{12,13}$, or their views may become stronger because of greater perceived consensus for their own views ${ }^{11}$.

Policy acceptability, acceptance and support have been used interchangeably within the literature, but represent distinct constructs ${ }^{1-3}$. Disagreement also exists within the policy and renewable energy technology (RET) literature regarding the definition of these constructs. Some authors distinguish among these terms on an attitudinal/behavioural dimension ${ }^{1-3,14}$ but, even so, do not agree which terms correspond to attitudes and which to behaviours. Acceptability has been said to correspond to attitudes and acceptance to behaviour ${ }^{14}$; conversely, acceptance to attitudes and support to behaviours ${ }^{1-3}$. Also, the terms have been distinguished temporally (that is, before (acceptability) and after (acceptance) implementation), while being unaligned with the attitudinal/behavioural dimension ${ }^{15}$. Different types of RET acceptance have also been proposedsocio-political acceptance, market acceptance, and community acceptance ${ }^{16}$.

Research measuring acceptance and support as distinct constructs shows that levels of 
acceptance are higher than support for the carbon policy in Australia ${ }^{1}$, fuel economy standards in the United States ${ }^{3}$, and energy infrastructure in the United Kingdom and Norway ${ }^{2}$. However, measurement concerns such as using a single item to measure the construct with different response formats ${ }^{1}$, or using the term 'in favour of' as a proxy for support in a two-item measure ${ }^{2}$, highlight the need for additional research.

Based on earlier work $^{1}$, we operationalize policy acceptance as a function of attitudes towards a policy at a given time (after implementation), and policy support as a function of acceptance with an additional behavioural component (action or intent). This conceptual formulation can also be extended to RET and suggests that acceptance may be a precondition of support. (Note that acceptability is also function of attitudes, but exists before policy implementation.)

Perceived effectiveness and fairness have both been linked to the acceptability (acceptance) of a proposed (implemented) environmental policy and support of a policy: greater perceived fairness/effectiveness leads to greater acceptability, acceptance and/or support ${ }^{1,3,4,17}$. Other individual characteristics are important too. For example, free-market ideology (FMI) describes the belief that markets should be allowed to operate unrestrained by government regulations; the market will resolve any problems through supply and demand dynamics ${ }^{18}$. Individuals endorsing a FMI are unlikely to accept or support climate policies ${ }^{1,3}$ because these policies are governmental regulations seeking to minimize negative market externalities (greenhouse gas emissions).

In Australia, climate action has been heatedly debated, with both Labor and Liberal governments advancing and regressing action ${ }^{19-21}$. The Clean Energy Legislative Package (CELP, also 
known as the carbon pricing policy, or inaccurately but more commonly as the carbon tax) was enacted in July 2012 by the Labor-led Australian federal government. The government sought to hold about 500 large industries responsible for the emissions they release by introducing a carbon price which would, in time, function as an emissions trading scheme (ETS) tied to the European Union's ETS. The government also created a compensation package for households indirectly impacted by the carbon price. At the time of policy implementation, the Opposition coalition strongly opposed the policy, instead favouring other measures such as market incentives. However, in the past years, leaders of the Liberal party (that is, Tirnbull, Howard) have supported an ETS (refs 19-21).

In June 2013, Kevin Rudd replaces Julia Gilard as leader of the Labor Party, thus becoming Prime Minister, and announced plans to fast forward the ETS, owing to high living $\operatorname{costs}^{19}$. The ETS was linked to the European Union's ETS one year earlier than planned, creating a floating marketbased price for carbon, instead of a fixed price. The CELP and associated ETS was later repealed in July 2014, after the conservation Liberal-National Party coalition won government in the September 2013 federal election, and Tony Abbot became the new Prime Minister. A new Direct Action Plan was enacted, in which an Emissions Reduction Fund provides incentives for abatement activities ${ }^{22}$.

We investigated whether the 2013 Australian federal election affected levels of acceptance and support for the Australian carbon policy. The carbon Policy was a key election issue, with different carbon policy outcomes depending on the election results. We measured acceptance and support of the carbon policy two weeks before (Time 1-T1 and two weeks after (Time 2-T2) the election through an online questionnaire distributed to a national sample of the Australian residents. We tested the following hypotheses: acceptance will be higher than support; acceptance and support will change between T1 and T2; and acceptance is necessary precondition of support 
(as one must accept a policy to support it).

At both T1 and T2, policy acceptance was significantly higher than support (T1: $t(515)=9.68$, $p<0.001 ; T 2: t(515)=11.64, p<0.001)$ and, surprisingly, acceptance and support were unchanged by the election (repeated-measures analysis of variance (ANOVA); acceptance: $F(1,515)=1.44, p>0.10$, support: $F(1,515)=0.01, p>0.10$; see Table 1$)$. Although acceptance and support levels varied predictably with the political party voted for, the basic findings of higher levels of acceptance than support and lack of change over time were consistent across party choice (see Table 1 and Methods for complete analysis).

Using hierarchical multiple regression analyses for T2 respondents ( $N=785)$, we tested whether perceived effectiveness, perceived fairness and FMI (all centred at the mean; entered on Step 1) and the interactions among these variables (entered on Step 2) predicted policy acceptance or support (see Table 2 and Methods for information on covariates, which did not impact the regression). Only the main effects were significant in these models (Acceptance: Step 1 adjusted $R^{2}=0.77, F(3,781)=873.65, p<0.001 ;$ Support: Step 1 adjusted $\left.R^{2}=0.69, F(3,781)=571.03, p<0.001\right)$. As predicted, greater perceived fairness and effectiveness were associated with increased acceptance and support of the policy, whereas greater FMI was and support of the policy (see Table 2). The addition of the interaction terms on Step 2 of these analyses failed to increase the amount of variance explained in either model $\left(\Delta R_{a c c}^{2}=0.00, \Delta R_{\text {supp }}^{2}=0.00 ;\right.$ although one interaction term (fairness * effectiveness) in the support model was significant, it failed to significantly increase the variance explained).

To examine our hypothesis that acceptance is a necessary precondition for support, we first 
cross-tabulated the distributions of acceptance and support among all participants at T2 (Methods and Supplementary Table 1; see Batel et al. 2013, for a similar analytic strategy, applied to a different context). For most respondents, acceptance and support aligned (accepting and supporting (33.2\%); not accepting and not supporting (21.4\%) or neutral on both (29\%)). In our sample, $2.8 \%$ of respondents accepted, but did not support the policy. Only $0.4 \%$ supported the policy but did not accept it. Starker evidence comes from comparing the proportion of those who accepted the policy from among those who supported it $(92.2 \%)$ and the proportion of those who supported the policy from among those who accepted it (71.7\%). These comparisons suggest acceptance is a necessary, but not sufficient, precondition for policy support-again highlighting these are two separate constructs.

A cross-lagged correlation analysis ${ }^{23}$ bolsters this conclusion: there was a significant difference between the correlation of acceptance at T1 with support at T2 (controlling for support at T1) and support at T1 and acceptance at T2 (controlling for acceptance at T1; $r^{\prime} \mathrm{s}=0.32$ and 0.17 respectively; $z=2.10, p<0.05)$, suggesting acceptance precedes support (see Methods for details).

Wefurther tested whether acceptance is a necessary precondition of support with a mediation analysis using AMOS with bootstrap estimation of the indirect effects (5,000 samples) among all respondents at T2. As shown in Fig. 1, we specified acceptance as the mediator and support as the dependent variable, with fairness, effectiveness and FMI as correlated predictors. Initial model testing revealed a better model fit constraining the direct path from FMI to support to 0 , therefore this path was omitted from the final model. Results indicated a good model fit, accounting for $77 \%$ of the variance in $\operatorname{support}\left(X^{2}(1)=1.11, p=0.29\right.$; comparative fit index $(\mathrm{CFI})=1.00$, root mean square error of approximation $(\mathrm{RMSEA})=0.01(\mathrm{Cl}: 0.00,0.10)$; standardized root mean square 
residual $(S R M R)=0.004)$. Acceptance was a significant mediator of all three predictors, as the $95 \%$ bias-corrected confidence intervals (Cls) for the indirect effect did not contain 0 (FMI: $-0.09, \mathrm{Cl}:-0.20$, -0.10; fairness: $0.26, \mathrm{Cl}: 0.21,0.33$; effectiveness: $0.28, \mathrm{Cl}: 0.22,0.34)$. An alternative model transposing acceptance and support did not fit the data as well $\left(\chi^{2}(1)=35.33, p=0.00 ; \mathrm{CFI}=0.98\right.$, RMSEA $=0.21(\mathrm{Cl}: 0.15,0.27) ; \mathrm{SRMR}=0.02)$, thus the current model is preferred. This suggests that acceptance is an important process through which FMI, fairness and effectiveness influence support. Fairness and effectiveness maintained significant, positive, direct effects in the presence of acceptance, whereas FMI did not.

Society-wide actions on climate change require broad acceptance and support of government policies and interventions. Our analyses offer novel evidence to conclude that acceptance is a necessary but not sufficient precondition of support, generally stronger than sup- port (support adding behavioural elements), and an important process through which FMI, fairness and effectiveness influence support. Together, this reinforces earlier results highlighting the necessity of measuring acceptance and support as distinct constructs ${ }^{1-3}$, while eliminating past measurement concerns (through measuring multiple items for each construct on similar response scales).

Although we have identified one important process, there may be others, not measured here, that should be explored. To do so, future climate policy research needs to measure acceptance and support as distinct constructs while investigating other variables. Furthermore, those who do not support the policy do not necessarily oppose it. Future research should attempt to disentangle opposition from lack of support, ambivalence from apathy, and 'rejection' from 'resistance' ${ }^{24}$.

Our second major conclusion relates to the stability of acceptance and support for Australia's proposed carbon pricing policy during a significant electoral upheaval where climate policy was an 
important area of contention. The lack of change was independent of party choice. Possibly, the stability of acceptance and support are related to the ambiguity around policy alternatives. Participants at T2 may have known that Abbott would try to repeal the CELP and institute the Direct Action Plan, but they would not have known the specifics of the alternative, as they were not released until after the survey.

Evaluation of the acceptance or support of a current policy should happen in a comparative policy context rather than in isolation from competing policy options. A limitation of our study is that we were unable to assess support and acceptability of the Direct Action Plan, and its perceived fairness and effectiveness, as the policy details were unknown at the time of the study and hence could not be included. The more fair and effective a policy is perceived to be, the more likely it is to be accepted and supported, therefore participation and/or procedural justice (a type of fairness) may be a key concern ${ }^{25,26}$ for future climate action. Research in many sustainability domains has considered the important role of participation, such as in planning and decisionmaking in renewable energy technology ${ }^{24}$, for sustainability science and community-based participatory research ${ }^{27}$, and in the implementation of European climate targets ${ }^{28}$. The CELP was specifically designed to address distributive justice issues via the household compensation plan; as such, we measured the distributive justice aspects of fairness in our study. Future studies should address participation and procedural justice concerns, if they are applicable for the climate policy.

Some policy-implementation implications arising from our study include the importance of ensuring public acceptance to undergird support. This can be done by, for example, communicating normative information ${ }^{29,30}$-in Australia, the carbon pricing legislation was not as 
unpopular as many, especially on the conservative side of Australian politics claimed, with nearly half of the population finding the policy acceptable and providing further evidence of pluralistic ignorance $^{11}$. However, that level of acceptance did not translate into effective support through the election. Clearly, policy acceptance does not equate to support (although it does mediate it), especially in contested arenas such as elections, where many issues are conflated into a single electoral point.

\section{Methods}

We used a within-subjects online survey experiment to investigate changes in support and acceptance before (T1) and after (T2) the 2013 federal election with Australian adults representing metropolitan, regional and rural areas online. Participants were recruited from a research-only panel administered by the research company ORU (http://www.theoru.com). ORU is an online fieldwork company with QSOAP Gold Standard and new global ISO 26363 standard accreditations. Through multisource and multichannel recruiting, ORU has a database of more than 300,000 individuals from across Australia. Participants were entered into a prize draw as an incentive to complete the survey. T1 surveying occurred approximately two weeks before the election in August 2013, and T2 occurred approximately two weeks after the election. Only T1 participants willing to be contacted at T2 were retained for data analysis ( $N=772,384$ males, 388 females). The T1 (T2) survey was open for six (seven) days before we reached the desired minimum sample size of 750 .

In addition, we used between-subjects design to measure testing bias. Testing bias was assessed to ensure that participating in the survey before the election did not influence the responses of those same participants (within-subjects) after the election. Post-election results from an independent sample taken 
at T2 were compared against the within-subjects sample at T2 and no significant differences were found on measures of acceptance or support ( $\left.p^{\prime} s>0.05\right)$, indicating there were no testing effects for our online survey.

For T1, we sent 14,500 invites via email within the panel. Of these, 1,551 respondents clicked the link from their computers, resulting in a $48.8 \%$ cooperation rate, and 5.3\% response rate. For T2 we recontacted the 772 T1 participants and recruited new participants. At T2, N=785 (388 males, 397 females); 516 were T1 participants and 269 were new participants. There was a 72.6\% cooperation rate; 66.8\% response rate within the $\mathrm{T} 1$ sample (772 invites sent, 711 click-ins), and a 55\% cooperation rate; 5.7\% response rate for those who were new at T2 (4,700 invites sent, 489 click-ins).

Questionnaires differed slightly for T1 and T2, reflecting prior consent and the recent change in government. Our measures are described below (see Supplementary Information for questionnaire). Our method is, in part, based on past work ${ }^{1}$, but improves on certain limitations by utilizing the same response format to measure multiple items for acceptance and support. In addition, our analytical approach differs from that past work. Unless noted, items were measured on five-point response scales.

Free-market ideology (FMI).

We measured FMI using the FMI scale in ref. 18 (see Supplementary Information), presenting items in random order to each participant. Responses were coded so a higher score aligned with endorsement of a FMI. 
Policy acceptance and support.

To ensure participants had a basic policy knowledge, the survey included a brief summary of the carbon policy taken from the government website. Next, acceptance and support items were randomly presented to each participant, along with the fairness and effectiveness items. The acronym CELP is used here for brevity, but was spelt out within questionnaire items.

We measured acceptance with four statements: 'How acceptable do you find the CELP?', 'To what extent are you in favour for or against the CELP?', 'To what extent do you agree or disagree with the implementation of the CELP?' and 'Do you prefer having the current carbon policy in place, as opposed to no carbon policy?'. Scores were averaged; higher numbers indicate greater acceptance (T1: $\alpha=$ $0.95 ; \mathrm{T} 2: \alpha=0.95)$.

Support was measured with three statements: 'How supportive are you of the carbon policy (The CELP)?', 'How willing are you to bear some of the costs resulting from the implementation of the CELP?', ‘How willing are you to take action to voice a positive opinion about the CELP, such as writing a letter or calling a representative?'. Scores were averaged; higher numbers indicate greater support (T1: $\alpha=0.79$; T2: $\alpha=0.82)$.

Perceived fairness and effectiveness.

Perceived fairness and effectiveness were each measured by two items: 'How fair do you think it is that some big industries now must pay for the carbon they emit, as mandated by the carbon pricing 
policy?', How fair do you think the compensation plan is for those affected by increased costs due to the carbon price?', 'How effective do you think the carbon pricing policy will be to help lower carbon emissions from industries in Australia?', 'How effective do you think the compensation plan is in reducing the financial impact of the carbon price on individuals?'. The two items for each measure were strongly correlated with each other $\left(\mathrm{T} 1: r_{\mathrm{eff}=} 0.65, r_{\text {fair }}=0.54 ; \mathrm{T} 2: r_{\mathrm{eff}}=0.65, r_{\text {fair }}=0.49 ; p^{\prime} s<0.01\right)$, supporting our decision to take the average of the two items as our measures of fairness and effectiveness. Higher numbers indicate greater fairness/effectiveness.

Voting preferences and behaviour.

At T1 we asked 'Which political party are you most likely to vote for in the next federal election?'; and at T2 'In the recent federal election for the House of Representatives, which of the following did you vote for?' and 'To which party did you give your second preference ?'. Response categories were: Labor Party, Liberal Party. National Party. Green Party, Independent, Family First, Other, Prefer not to say. Additionally, there was an 'I don't know' category at T1.

Demographics.

We assessed gender, income, age and education. Six response categories were included for income, varying from ' $0-\$ 18,200$ ' to ' $\$ 180,001$ and over.' These categories were chosen to replicate the cutoff points for the compensation package within the carbon policy, based on household 
incomes established by the Australian Government. Additionally, we included a 'prefer not to respond' category.

Acceptance and support.

During both time periods, policy acceptance was higher than support. Of the 516 participants who completed both surveys, $46.3 \%$ found the policy acceptable, $28.1 \%$ unacceptable, and $25.6 \%$ were neutral or ambivalent at T1. In contrast, $35.9 \%$ supported the policy, 33.5\% did not support the policy, and $30.6 \%$ were neutral or ambivalent. At T2, $45.7 \%$ found the policy acceptable, $25.4 \%$ unacceptable, and $28.9 \%$ were neutral or ambivalent. In contrast, $36.4 \%$ supported the policy, $33.3 \%$ did not support the policy, and $30.2 \%$ were neutral or ambivalent. These findings were further supported by significant mean differences between acceptance and support for both time periods (Table 1). As hypothesized, participants showed greater acceptance than support of the policy at T1 $(t(515)=9.68, p<0.001)$ and $\mathrm{T} 2(t(515)=11.64, p<0.001)$. Both acceptance and support were stable across the election time: a repeated-measures ANOVA showed no significant change in acceptance or support from T1 to T2, ( $\left.p^{\prime} s>0.05\right)$.

Covariates.

Preliminary regression analyses for covariates revealed that age and gender were not significantly related to support or acceptance-and were therefore dropped from subsequent 
analyses. Education and income were significant predictors of acceptance $(b=0.14, p<0.01 ; b=-0.11$, $p<0.05)$ and education was a significant predictor of support $(b=0.19, p<0.01)$. As the inclusion of these variables did not affect the significance of other variables within the hierarchical multiple regression models, they were removed from the models for sake of parsimony and comparability. In addition, education and income were analysed for repeated-measures effects, to see if the covariates influenced changes in acceptance or support over time. No covariate significantly impacted the relationship of acceptance or support over time. Therefore, the covariates were excluded from analysis of variance procedures.

Analysis of variance by voting.

Political party voting intention at T1 was closely split between the Labor Party $(n=148,28.7 \%)$ and the Liberal Party $(n=146,28.3 \%)$, with the remainder spread among smaller parties. At T2, selfreported first preference votes (the political party to which the participants gave their first vote to) were equally split between the Labor Party $(n=164)$ and the Liberal Party $(n=165)$, with other parties in smaller quantities (Table 1).

Analysis of variance (ANOVA) was conducted to see whether supporters of different political parties significantly differed in carbon policy acceptance and support. This analysis included only Labor, Liberal and Greens Party supporters owing to small cell sizes of other categories and lack of comparability for 'prefer not to say' or 'other.' The analyses revealed significant main effects for voting behaviour on acceptance and support and both T1 and T2 (Acceptance: $F(2,373)=79.99$, 
$p<0.001 ; F(2,373)=73.46, p<0.001$, respectively; Support: $F(2,373)=66.81, p<0.001$;

$F(2,373)=57.68, p<0.001$, respectively $)$. Tukey's HSD tests showed significant differences between Greens and Liberal supporters, and Liberal and Labor supporters at T1 and T2, as well as Greens and Labor at $\mathrm{T} 2$, but only for support ( $\mathrm{p}^{\prime} \mathrm{s}<0.05$ ) (Table 1). Highest levels of acceptance and support of the carbon policy occurred in Greens Party supporters at both T1 and T2, whereas Liberal Party supporters reported the lowest levels of acceptance and support. Paired samples t-tests indicated no changes in acceptance or support from T1 to T2 for Labor, Liberal or Greens supporters $\left(p^{\prime} s<0.05\right)$.

Cross-lagged correlations.

Owing to high zero-order correlation between the acceptance and support at both time periods, we computed cross-lagged correlations on the residuals ${ }^{23,31}$. In effect, we used the correlation between acceptance at T1 with support at T2, while controlling for support at T1 $\left(r_{\text {acc1supp2.supp } 1}\right)$ and the correlation between support at $\mathrm{T} 1$ and acceptance at $\mathrm{T} 2$, while controlling for acceptance at $\mathrm{T} 1$ $\left(r_{\text {supp1acc2.acc1 }}\right)$, along with the two synchronous correlations of the residuals $\left(r_{\text {acc1supp1 }}\right.$ and $\left.r_{\text {acc2supp2 }}\right)$, and the two autocorrelations of the residuals ( $\operatorname{acc} 1$ acc2 2 and $r$ supp1supp2) to test the equality of the cross-lagged correlations $^{23}$ using our within-subjects sample ( $N$ 516). We find that the cross-lagged correlations of the residuals are significantly different from each other $\left(r_{\text {acc1supp2.supp } 1}=0.32\right.$, $r_{\text {supp1acc2.acc1 }}=0.17, z=2.10, p<0.05 ;$ ref. 32), giving further evidence supporting the argument hat acceptance of a policy is a precondition for support (that is, indicates causality). 
Figures

Table 1| Mean values with standard deviations of acceptance and support by party (first preference votes).

Liberal party Labor party Greens party National party Independent Family first Prefer not to say Other

Total

\begin{tabular}{|c|c|c|c|c|c|c|c|c|c|c|}
\hline \multirow[t]{2}{*}{ Acceptance } & $\mathrm{T} 1$ & $2.49(1.06)^{a}$ & $3.74(0.95)^{b}$ & $3.94(0.83)^{b}$ & $2.57(1.00)$ & $3.06(1.45)$ & $3.06(1.06)$ & $3.12(0.77)$ & $3.13(1.05)$ & $3.17(1.14)^{d}$ \\
\hline & $\mathrm{T} 2$ & $2.56(1.14)^{a}$ & $3.76(0.87)^{b}$ & $3.97(0.85)^{b}$ & $2.67(1.04)$ & $3.28(1.40)$ & $3.25(0.94)$ & $3.11(0.70)$ & $3.02(1.09)$ & $3.20(1.13)^{d}$ \\
\hline \multirow[t]{3}{*}{ Support } & $\mathrm{T} 1$ & $2.36(0.94)^{a}$ & $3.38(0.96)^{b}$ & $3.71(0.75)^{b}$ & $2.38(0.68)$ & 3.13 (1.15) & $2.74(0.76)$ & $2.78(0.78)$ & $2.76(1.03)$ & $2.92(1.04)^{\mathrm{e}}$ \\
\hline & $\mathrm{T} 2$ & $2.40(1.03)^{a}$ & $3.35(0.92)^{b}$ & $3.74(0.79)^{c}$ & $2.51(0.97)$ & $2.77(1.43)$ & $2.93(0.74)$ & $2.85(0.70)$ & $2.67(1.07)$ & $2.92(1.06)^{\mathrm{e}}$ \\
\hline & $n$ & 165 & 164 & 47 & 15 & 16 & 9 & 55 & 45 & 516 \\
\hline
\end{tabular}

Scores on the acceptance and support scales could vary from 1 to 5 . Values in a row with a common superscript letter do not differ significantly ( $p>0.05$ ); those with different subscripts differ

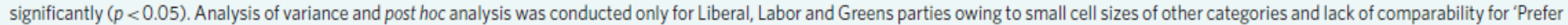

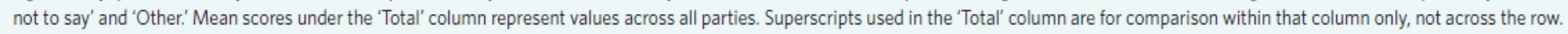


Table 2 | Hierarchical multiple regression models for policy acceptance and support.

\section{Dependent variables}

\begin{tabular}{|c|c|c|c|c|}
\hline & & & Acceptance & Support \\
\hline \multirow[t]{6}{*}{ Step 1} & Fairness & $b(\mathrm{SE})$ & $0.44(0.03)^{\text {k*k*k }}$ & $0.36(0.03)^{* k * k}$ \\
\hline & & {$[\mathrm{Cl}] s r^{2}$} & {$[0.38,0.50] 0.53$} & {$[0.30,0.42] 0.35$} \\
\hline & Effectiveness & $b(\mathrm{SE})$ & $0.46(0.03)^{* * * *}$ & $0.48(0.03)^{* * * *}$ \\
\hline & & {$[\mathrm{Cl}] s r^{2}$} & {$[0.41,0.52] 0.53$} & {$[0.42,0.54] 0.50$} \\
\hline & FMI & $b(\mathrm{SE})$ & $-0.25(0.03)^{\text {*k*k }}$ & $-0.18(0.04)^{* * * *}$ \\
\hline & & {$[\mathrm{Cl}] s r^{2}$} & $\begin{array}{l}{[-0.31,-0.19]} \\
-0.27\end{array}$ & $\begin{array}{l}{[-0.25,-0.11]} \\
-0.18\end{array}$ \\
\hline \multirow[t]{6}{*}{ Step 2} & Fairness* & $b(\mathrm{SE})$ & $-0.01(0.02)$ & $0.04(0.02)^{*}$ \\
\hline & & {$[\mathrm{Cl}] s r^{2}$} & $\begin{array}{l}{[-0.04,0.03]} \\
-0.01\end{array}$ & $\begin{array}{l}{[0.01,0.08]} \\
0.08\end{array}$ \\
\hline & Fairness* FMI & $b(\mathrm{SE})$ & $-0.02(0.04)$ & $-0.03(0.05)$ \\
\hline & & {$[\mathrm{Cl}] s r^{2}$} & $\begin{array}{l}{[-0.10,0.06]} \\
-0.02\end{array}$ & $\begin{array}{l}{[-0.11,0.06]} \\
-0.02\end{array}$ \\
\hline & Effectiveness* & $b(\mathrm{SE})$ & $0.03(0.04)$ & $-0.04(0.05)$ \\
\hline & & {$[\mathrm{Cl}] s r^{2}$} & $\begin{array}{l}{[-0.05,0.10]} \\
0.02\end{array}$ & $\begin{array}{l}{[-0.12,0.05]} \\
-0.03\end{array}$ \\
\hline$\Delta R^{2}$ & & & 0.00 & 0.00 \\
\hline
\end{tabular}

Cell entries for acceptance and support in line 1, are unstandardized ordinary least squares regression coefficients (b), standard errors (SE) are in parentheses following. The second line is the $95 \%$ confidence interval $[\mathrm{Cl}]$ for $b$, with squared partial correlation coefficient following. This is repeated for Step 1 and Step 2. The last line in the table represents the change in the multiple correlation coefficient squared $\left(\Delta R^{2}\right)$. See Supplementary Table 2 for correlation table. ${ }^{*} p \leq 0.05,{ }^{* * *} p<0.001$. 
Figure 1 Path model. This model shows acceptance mediating the effects of FMI, effectiveness and fairness with standardized regression estimates. The curved lines indicate covariance and associated correlation. All paths are significant, $p^{\prime} s<0.01$.

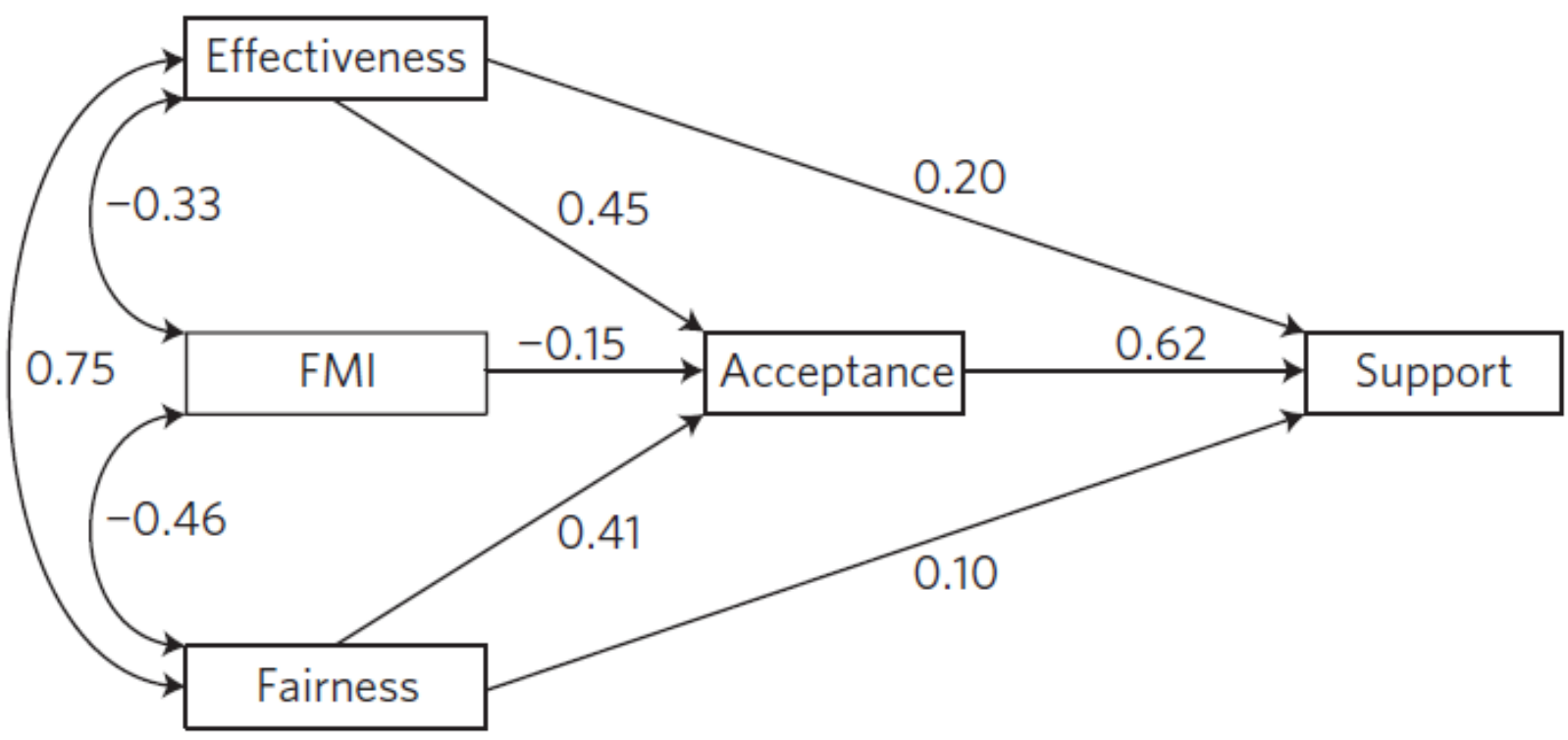


References

Dreyer, S. J. \& Walker, I. Acceptance and support of the Australian carbon policy. Soc. Justice Res. 26, 343-362 (2013).

Batel, S., Devine-Wright, P.\& Tangeland, T. Social acceptance of low carbon energy and associated infrastructures: A critical discussion. Energy Policy 58, sity of measuring acceptance and support as distinct constructs ${ }^{1-3}$, while eliminating past measurement concerns (through measuring multiple items for each construct on similar response scales). 1-5 (2013).

Dreyer, S. J., Teisl, M. F. \& McCoy, S. K. Are acceptance, support, and the factors that affect them, different? Examining perceptions of U. S. fuel economy standards. Transp. Res. D 39, 65-75 (2015).

Schuitema, G., Steg, L. \& Forward, S. Explaining differences in acceptability before and acceptance after the implementation of a congestion charge in Stockholm. Transp. Res. A 44, 99-109 (2010).

Winslott-Hiselius, L., Brundell-Freij, K., Vagland, Å. \& Byström, C. The development of public attitudes towards the Stockholm congestion trial. Transp. Res. A 43, 269-282 (2009).

Santos, G. Urban congestion charging: A comparison between London and Singapore. Transp. Rev. 25, 511534 (2005).

Borland, R., Owen, N., Hill, D. \& Chapman, S. Changes in acceptance of workplace smoking bans following their implementation: A prospective study. Prev. Med. 19, 314-322 (1990).

Lam, S.-P. Predicting support of climate policies by using a protection motivation model. Clim. Policy 15, 321-338 (2015).

Zajonc, R. B. Attitudinal effects of mere exposure. J. Pers. Soc. Psychol. Monogr. Suppl. 9, 1-27 (1968).

\section{(1989).}

R. F. Exposure and affect: Overview and meta-analysis, 1968-1987. Psychol. Bull. 106, 265-289

Leviston, Z., Walker, I. \& Morwinski, S. Your opinion on climate change might not be as common as you think. Nature Clim. Change 3, 334-337 (2012).

Festinger, L. A Theory of Cognitive Dissonance (Stanford Univ. Press, 1957).

Schade, J. \& Baum, M. Reactance or acceptance? Reactions towards the introduction of road pricing. Transp. Res. A 41, 41-48 (2007).

Huijts, N. M. A., Molin, E. J. E. \& Steg, L. Psychological factors influencing sustainable energy technology acceptance: A review-based comprehensive framework. Renew. Sustain. Energy Rev. 16, 525-531 (2012). Schade, J. \& Schlag, B. Acceptability of urban transport pricing strategies. Transp. Res. F 6, 45-61 (2003). Wüstenhagen, R., Wolsink, M. \& Bürer, M. J. Social acceptance of renewable energy innovation: An introduction to the concept. Energy Policy 35, 2683-2691 (2007).

Steg, L., Dreijerink, L. \& Abrahamse, W. Why are energy policies acceptable and effective? Environ. Behav. 38, 92-111(2006).

Heath, Y. \& Gifford, R. Free-market ideology and environmental degradation: The case of belief in global climate change. Environ. Behav. 38, 48-71 (2006).

9. Talberg, A., Hui, S. \& Loynes, K. Australian Climate Change Policy: A Chronology (The Parliament of Australia, 2013). Jotzo, F. Australia's carbon price. Nature Clim. Change 2, 475-476(2012).

Head, L., Adams, M., McGregor, H. V. \& Toole, S. Climate change and Australia. WIREs Clim. Change 5, 175-197 (2014).

Repealing the Carbon Tax (Australian Government, Department of Environment, 2014);

http://www.environment.gov.au/topics/cleaner-environment/clean-air/repealing-carbon-tax

Kenny, D. A. Correlation and Causality (John Wiley, 1979).

Rau, I., Schweizer-Ries, P. \& Hildebrand, J. in Vulnerability, Risks, and Complexity: Impacts Global

Change on Human Habitats (eds Kabisch, S. K., Kunath, A. K., Schweizer-Reis, P. \& Steinführer, A. S.) 177191 (Hogrefe Publishing, 2012). Thibaut, J. W. \& Walker, L. Procedural Justice: A Psychological Analysis (L. Erlbaum Associates, 1975). Tyler, T. R., Boeckmann, R. J., Smith, H. J. \& Huo, Y. J. Social Justice in Diverse Society (Westview Press, 1997). 
27. Silka, L. Community research in other contexts: Learning from sustainability science. J. Empir. Res. Hum. Res. Ethics 5, 3-11 (2010).

28. Wolkinger, B. et al. Implementing Europe's climate targets at the regional level. Clim. Policy 12, 667-689 (2012).

29. Cialdini, R., Reno, R. \& Kallgren, C. A focus theory of normative conduct: Recycling the concept of norms to reduce littering in public places. J. Pers. Soc. Psychol. 58, 1015-1026 (1990).

30. Kallgren, C. A., Reno, R. R. \& Cialdini, R. B. A focus theory of normative conduct: When norms do and do not affect behavior. Pers. Soc. Psychol. Bull. 26, 1002-1012 (2000).

31. Steiger, J. H. Tests for comparing elements of a correlation matrix. Psychol. Bull.87, 245-251 (1980).

32. Lee, I. A. \& Preacher, K. J. Calculation for the Test of the Difference Between Two Dependent Correlations with No Variable in Common (2013); http://quantpsy.org 


\section{Acknowledgements}

We gratefully acknowledge funding support by the Commonwealth Scientific and Industrial Research Organisation's Climate Adaptation Flagship; the Maine Sustainability Solutions Initiative (supported by National Science Foundation award EPS-0904155 and Maine EPSCoR at the University of Maine); and the Maine Agricultural and Forest Experiment Station. We also thank the Center for Statistics and the Social Sciences, the Communication and Marketing Team in the College of the Environment (both at the University of Washington), and S. Newcomb for providing feedback on manuscript drafts. 